\title{
CORPOREIDADE: O CORPO, ENTRE A FILOSOFIA E O DIREITO.
}

\section{Camila Queiroz}

\section{RESUMO:}

Esse artigo se propõe a estabelecer um diálogo entre as contribuições de Marcel Mauss e Maurice Merleau-Ponty, no concernente às analises engendradas a respeito do corpo, que se faz à luz da corporeidade, um instrumento relacional com o entorno. Inobstante, a fundamentação principiológica de ambos, os dois se propuseram a superação do egrégio vértice inaugurado por Descartes - o pensamento e a matéria. Ademais, o texto pretende demonstrar a tangibilidade de diálogo entre suas convicções, bem como abarcar concepções filosóficas, manifestando seu cunho transdisciplinar. Busca-se a validação das bases antropofilosóficas para a consolidação do Direito ao Corpo, assentado nos preceitos fundamentais.

PALAVRAS-CHAVE: Corpo; Corporeidade; Fundamentos filosóficos do direito ao corpo; Transdisciplinaridade.

\section{CORPOREITY: THE BODY, BETWEEN PHILOSOPHY AND LAW.}

\begin{abstract}
:
This article aims to establish a dialogue between the contributions of Marcel Mauss and Maurice Merleau-Ponty, concerning the engendered analyses about the body, which is made in the light of corporeity, a relational instrument with the surroundings. Nevertheless, the principleof both, the two proposed to overcome the vertex egrégio inaugurated by Descartes thought and matter. Moreover, the text intends to demonstrate the tangibility of dialogue between its convictions, as well as to understand philosophical conceptions, manifesting its transdisciplinary nature. It seeks the validation of anthropo-philosophical bases for the consolidation of the Right to the Body, based on the fundamental precepts.
\end{abstract}

KEYWORDS: Body and Corporeality, Philosophical Foundations of the Right to the Body, Transdisciplinarity.

\section{INTRODUÇÃO}

Esse trabalho tem por escopo, um esboço paralelamente tracejado entorno das colaborações de Marcel Mauss e Maurice Merleau-Ponty, no tangente às perspectivas concebidas pelo processo simbiótico entre o corpo e a corporeidade. Ambos, propuseram-se a transpor a dicotomia instituída por Descartes entre a substancia pensante e a matéria.

\footnotetext{
${ }^{1}$ Graduada em Direito pela Pontifícia Universidade Católica de MG. Pós graduada em Ciências Penais e Direito ambiental e minerário pela Pontifícia Universidade Católica de MG. Mestranda em Instituições Sociais, Direito e Democracia pela Fundação Mineira de Educação e Cultura - FUMEC.

Email:camilaqueiroz1205@gmail.com.https://orcid.org/0000-0002-4593-7441.ID lattes.cnpq.br/5847950094107469.
} 
Empenharam-se em debater e desenvolver contornos de uma cognição que ultrapassasse o clássico paradigma logrado pelos domínios naturais, em busca de que outros os tornassem capazes de colaborar para a instituição de um estudo do homem como ser social- a ciência humana.

O Primeiro, Marcel Mauss (1872-1950), sobrinho de Durkheim, com quem atuou até 1917 (ano de falecimento de Durkheim), compartilhava seus ideais, admoestando-se que para a constituição de uma cognição social, necessitava-se uma visão dos fatos sociais como coisas, no intuito de compararem-nos com os demais fenômenos inerentes a vida coletiva.

Ambos, perquiriam ser premente a estruturação de uma aproximação que abarcasse a reflexão humana não como mera consequência de condições individuais de pensamento, nem tampouco, como decorrência da analise social, como um sistema de práticas exóticas. Fez-se nesse contexto, a organização das abordagens de Mauss acerca do homem, assim como, deuse nesse sentido a elaboração de seus elementos basilares, tais como os de Fato Social Total, Homem Total, Dádiva, Técnicas do Corpo e outras mais. Embasando-se por um amparo sociológico, o autor baseou-se primordialmente em percepções como as de "convenções" e de "costumes" com intenção de demonstrar a forma como as pessoas "exercem valia de seus corpos" $^{1}$.

Posteriormente, Maurice Merleau-Ponty (1908-1961) censurou o nomeado pensamento de sobrevoo, fundado por Descartes, o que advém-se da fragmentação convicçãomundo. Para Maurice, essa compartimentalização origina-se na parcialidade filosófica, bem como no comportamento objetivista das ciências.

Primeiramente, converte-se o mundo numa representação de si próprio, prestigiando um aspecto acautelado e apartado do espectador no que refere-se as coisas. Já na segunda situação, reduziu-se o objeto aos seus atributos específicos, como se, para seu entendimento,

\footnotetext{
${ }^{1}$ Expressão utilizada pelo autor em seu texto "As técnicas do corpo", ao asseverar que o corpo faz-se o primordial e por conseguinte mais relevante mecanismo do homem. Para superar uma visão utilitarista, à qual a redação possa pospor, Mauss tinha o intuito de apontar como nossas técnicas corporais são convencionais e nossas atitudes nada têm de inatas, contudo são geradas por "regras da coletividade"
} 
fizessem-se necessários substancialmente a pormenorização e a inquirição de suas peculiaridades, congruentemente ao empenhado pelas ciências da natureza (Chauí, 1980).

Merleau-Ponty fez-se legitimado como fenomenólogo, primordialmente por sua ideologia acerca da compreensão humana. Suas pesquisas consubstanciam-se na noção de que o corpo faz-se conjuntura primeva do amago humano, e, assim, por intermédio dele, tomam-se conhecimento da forma de situar-se no mundo.

Não subsiste, nesse sentido, a afirmação de um espectador incondicional, na sociologia de Durkheim, nem na psicanálise de Freud - onde o corpo faz-se a área de assentamento dos rastros constantes nas memorias das experiências preliminares pueris, por intermédio do Eu poder-se-á compor, sendo por conseguinte, o local de onde insurge o ímpeto, e também o mecanismo de alcançar à sua satisfação, quer seja por meio do gozo ou no aborrecimento conjuntamente em ascensão nas décadas exordiais do século XX. Bem como, não obstante, inexiste um objeto cabal.

Essa inquietação, em forma de crítica a ideologia de sobrevoo da ciência, encontra-se de certo modo, na obra de Mauss. Apesar de coadunar-se com Durkheim no que tange ao fato social ser vislumbrado como "coisa" e que far-se-ia insegmentável ao elóquio num plano anímico. O autor aquiescia, que o fato social somente poder-se-ia ser amplamente depreendido, observando-se sua corporificação numa vivencia peculiar.

Vale ressaltar, que as práticas de um povo far-se-iam "encarnadas" em cada indivíduo que dessa coletividade fizesse parte, e apenas por intermédio de sua paridade, tal como incorporada na vivencia singular, poder-se-iam ser concebidos.

Nesse contexto, ainda que aborde-se as teses dos autores sem maiores especificações, buscar-se-á maiores reflexões em suas produções, substancialmente no que refira-se ao modo como abordavam o tema "corpo". Acredita-se, inobstar-se os afastamentos nitidamente perceptíveis entre os dois, faz-se plausível avizinha-los e, sobretudo, acomoda-los numa interlocução, na diligencia não apenas de compreensão, como de ampliação da herança por eles deixada, no que diga respeito ao olhar sobre corpo e corporeidade vigentes nas pesquisas hodiernas. 


\section{AS CONVICÇÕES DE MARCEL MAUSS}

Em seu registro de maior notabilidade, $\mathrm{O}$ ensaio sobre a dádiva, Marcel avolumou o significado de Fato Social Total (FST). Essa abordagem incorre na cognição de que, em quaisquer realizações do ser humano, podem encontrar-se nas esferas sociológica, psicológica e ainda fisiológica. O triplo questionamento só faz-se plausível de alcance, em razão de tais dimensões constituírem uma similitude, quando interpretadas através da experiência de quaisquer indivíduos membros de determinada coletividade (Lévi-Strauss, 1974).

Com fundamento nos mesmos rudimentos logrados para a elaboração da convicção de FST que Mauss, tardiamente, em “As técnicas do corpo", referiu-se à percepção de Homem Total (HT). Nesse ensaio, com teor substancialmente voltado ao corpo e a forma como os indivíduos, sociedade por sociedade, "exercem valia de seus corpos". Considerando-se o momento de sua produção, informação altamente considerável nesse caso, em que seja qual for o afastamento a respeito da temática deparava-se com múltiplas balizas teoréticas e, até mesmo, de linguagem, a composição de Mauss sobre as valias do corpo alvitra pressuposições modernas. Opta-se por trazer a compreensão a visão de "valias do corpo", sem redundar-se um aprisionamento a ótica utilitarista a que a dicção possa remorar.

Não pretende-se abdicar o plausível vácuo abstrato vigente numa proposição que, rigorosamente pelas balizas já mencionadas, apresenta-se vestígios da convicção dualista, que consubstancia a separação do "ser" e do "ter" um corpo. Atentem-se ao fato da intenção de Mauss voltar-se exatamente a superação de tais entendimentos a respeito do ser humano, bem como sobre o corpo. Faz-se imperativo relembrar, ainda, das limitações encontradas nas abordagens hodiernas com esse teor, as quais, ulteriormente a quase cem anos dos escritos de Mauss, manifestam-se vestígios de tal dualidade e ainda não encontrar-se sequer o melhor método de suplantá-lo.

Em decorrência de uma outra convicção manifesta no texto das "técnicas corporais" que pode perceber-se um dos primordiais espólios de Mauss: a concepção de "imitação prestigiosa". Marcel enuncia sobre a imitação e a aprendizagem dos gestos de indivíduos que, de certo modo, lograram sucesso. Ao pensar-se na rotina diária das sociedades hodiernas, pode-se especificar uma sucessão de categorias que servem-se, não apenas como critérios de 
êxito (no sentido maussiano), mas também, como padrões a serem auferidos por aqueles que ensejam-se enquadrar, como, por exemplo, ser magro, ser bonito, ser famoso, ser puro, ser habilidoso, ser forte, etc.

Ponderando-se ainda, a respeito de "proveitos do corpo", deve-se considerar a proximidade do vocábulo com o que Pierre Bourdieu pensava acerca do "habitus"2. Influenciado, inicialmente, pelo que Mauss afirmava em relação ao hábito, Bourdieu alarga a definição e torna-a conhecida. Importa ressaltar que, na construção daquilo que nomeamos "habitus" em sua ideologia, Bourdieu aproximava-se suas analises à ideia de "incorporação". $\mathrm{Na}$ opinião do autor, aprende-se através do corpo, onde a ordem social inscreve-se através de embates constantes. Nessa senda, pensar-se em "incorporação" faz-se refletir que, ela dá-se pela construção do entendimento prático (coletivo e individual).

De acordo com Wacquant (2002, p.118), substancialmente inspirado pela ideologia de Bourdieu, interioriza-se um encadeamento de arranjos inerentemente mentais e físicos no decurso do tempo. Segundo ele, o processo socializador adequado a algo ou a determinado grupo derivam-se da aclimatação dos gestos e dos comportamentos. Wacquant assevera que o "habitus" insurge de um arrazoado prático, que, "incrustado profundamente no corpo, eludese à uma vertente da precedência individual". Assim sendo, a conotação prática delineia as "escolhas" que não abandonam a sistematização, apenas por não serem estatuídas.

Influenciando a escrita de diversos autores, os desígnios de Mauss acerca do pensamento humano de maneira globalizante faz-se expressivo. Buscando-se correlacionar os prismas biológico, psicológico e social, no que concerne ao que ele nomeou de "usos do corpo", o autor protege a convicção que todo método corporal é clássico. Numa tentativa de relativização da exaltação biológica que, continuamente recidiva sobre o corpo, o autor examina-o como uma edificação cultural intrínseca a cada grupo social, vez que seres humanos distintos, utilizam-se do próprio corpo de maneiras diversas e distintas (Mauss, 1974). 
${ }^{2}$ É relevante relembrar que, quando Bourdieu menciona o evento do "criado do café", de Sartre (ver Bourdieu, 2009, p.88), para asseverar que os costumes são encarnados nos corpos e nas vestes "habitadas por um certo habitus". Bourdieu adverte para o fato de que o enredo inscrito no corpo do criado manifesta um "habitus", um costume. Porém, isso não quer dizer, que ele tenha aprendido a ser criado de café reproduzindo outros criados de café, como paradigmas constituídos. Há a identificação com a função de criado de café, assim como a criança identifica-se com o seu pai (social) e adota, sem precisar simular, um modo parecido de se comportar e que parece constituir-se o ser social do adulto perfeito.

$\mathrm{Na}$ perspectiva de Mauss, o corpo faz-se, concomitantemente, "insumo" e "mecanismo" da cultura, levando-o a afirmação de que não faz-se plausível encontrar um costume natural num adulto. Os movimentos gestos mais "naturais" são construídos por regras da coletividade. Tem-se uma constituição social do corpo e do gesto, contudo que impõe-se de forma diferenciada a cada indivíduo, bem como em concordância com seu horizonte de ser e estar no mundo.

Depara-se portanto, com uma das maiores demandas vigentes na discussão hodierna tangente à temática, ou seja, a forma como alguns pesquisadores irrompem-se atuando com olhares deterministas sobre o corpo. A ideologia de Mauss no que refere-se ao corpo como insumos e instrumento agente da cultura, advém-se uma forma de conhecimento no qual o corpo determina-se social ou culturalmente. Verdadeiramente, habituou-se a engendrar críticas exatamente à óticas opostas, significa dizer, aquela que opera-se a partir da ideologia de um determinismo biológico e subtrai ou censura as inferências da vivencia social, tanto na civilidade quanto na estruturação dos corpos. Não que a retorica de Mauss apresente-se de modo determinista, contudo, faz-se nesse contexto o incremento ao debate proposto por Merleau-Ponty.

\section{OS CONTRAPONTOS DE MAURICE MERLEAU-PONTY}

Na elaboração da obra Signes, em 1960, Merleau-Ponty enunciou um capítulo chamado "De Mauss a Claude Lévi-Strauss", em salvaguarda à apropriação da cadeira de Antropologia Social por Lévi-Strauss, no Collège de France. Cuida-se da aclamação do autor à relevância da Antropologia, ao esclarecer-se a função do observador no tocante ao seu alvo investigado, que considera-se também sujeito. Ato continuo a essa contribuição, não faz-se premente anuir uma escolha entre o indivíduo e a coletividade. 
Existe atualmente, a contemplação da comunicação das consciências individuais, numa qualidade de intersubjetivo, vez que o objeto investigado não trata-se de coisa inanimada, contudo, de um ser humano, diferindo-se em alguns pormenores, mas ainda assim tão cheio de humanidade quanto o próprio pesquisador. O que faz-se interessante ao filósofo na Antropologia "é exatamente o tomar o homem como o é, em sua conjuntura afetiva de vida e conhecimento" (Merleau-Ponty, 1980, p.205).

Nessa senda, faz-se curioso distinguir que, de igual modo sendo o fenomenólogo renomado por sua proposição da teoria da percepção, onde o corpo faz-se categórico de subjetividade, Merleau-Ponty aponta a intersubjetividade manifesta numa "condição corpórea" que dá-se entre atuações particulares e gerais. A ascendência de Mauss e LéviStrauss na fenomenologia de Merleau-Ponty redunda-se imperiosa, rigorosamente por vivificar a ruptura de uma convicção de essência somente interna.

Visto que Merleau-Ponty, perquiri infringir com a contraposição entre natureza e cultura, elabora-se uma ideia de corporeidade que sopesa, inicialmente, o corpo (carne) como forma de assimilação suscetível de significado, o qual não faz-se plausível de ser diminuído à diretriz da índole humana. Se, na concepção dele, as acuidades e entendimentos do mundo fundamentam-se num corpo biológico, paralelamente definem-se pela coletividade e pela cultura inerente ao grupo em especifico.

Ao considerar-se a estruturação psicológica, Merleau-Ponty indica, em "Fenomenologia da percepção", que o corpo faz-se ponto fulcral da experimentação com os outros e com o mundo. O corpo proporciona e instaura a vida e a compleição do ser no mundo. Em "O visível e o invisível”, o autor implementa-se a tratar o corpo como um axioma ontológico, enfatizando-se a vivencia individual encarnada que, passando-se pela mente do ser aquiesce o domínio das diversas definições que alinham o esquema corporal (MerleauPonty, 1992).

Se, na concepção de Mauss, a técnica e a tradição são vocábulos mais vultuosos, para Merleau-Ponty, o conhecimento acerca de carne justapõe-se:

A carne não é matéria, não é espírito, não é substância. Seria preciso, para designá-la, o velho termo elemento, no sentido em que era empregado para falar-se da água, do ar, da terra e do fogo, isto é, no sentido de uma coisa geral, meio caminho entre o 
indivíduo espácio-temporal e a ideia, espécie de princípio encarnado que importa um estilo de ser em todos os lugares onde se encontra uma parcela sua (Merleau-Ponty, 1992, p.135).

Nesse mesmo direcionamento, Furlan e Bocchi (2003) examinavam o ânimo tangível da acepção. Os sentidos situados na carne descortinam em direção ao gesto. Os autores apropriam-se da teoria de Merleau-Ponty, ao pensarem o gesto como movimento expressivo originário da linguagem. Por fim, para o autor, a movimentação corporal acarreta a comunicação visto que, ao passo em que articula e fala, o corpo manifesta acuidade e significação.

Merleau-Ponty assevera que só consegue-se a compreensão no que refere-se a intencionalidade de outrem, através do próprio corpo. Desse modo, verifica-se em sua acepção um lugar especial para o corpo, a ele atribui-se um vigor expressivo que lhe é indissociável: o corpo faz-se intencionalidade que exterioriza-se, e que oculta a própria significação (Furlan; Bocchi, 2003, p.449).

Nessa perspectiva, o corpo tanto faz-se manifestação de um comportamento como um edificador de sentido, vez que, antes da manifestação, existe somente um afastamento. $\mathrm{O}$ preenchimento dos lapsos dessa ausência faz-se o gesto. Cuja presença do outro faz-se pela carne. Merleau-Ponty preceitua que

um outro é esse corpo animado de todos os tipos de intenções, sujeito de ações ou afirmações das quais me lembro e que contribuem para o esboço de sua figura moral para mim. [...] e a aparência total desse corpo parece-nos conter todo um conjunto de possibilidades das quais o corpo é a presença propriamente dita (Merleau-Ponty, 2004, p.43).

A corporificação, nas palavras do autor, não apenas exterioriza a existência do outro, bem como torna-os acautelados de tal presença. Por conseguinte, Merleau-Ponty, assevera só sentir-se a existência após entrar-se em contato com os demais. A consciência de si próprio dá-se no regresso, ou seja, ulterior a "frequentar-se" o outro.

No sentido lato, a fenomenologia, conjuntamente com o aporte de Merleau-Ponty, em especial, inauguraram-se múltiplos olhares de reflexão numa convicção consecutiva e ainda assim consubstanciam-se insumos metodológicos e conceituais, como na perspectiva da filosofia francesa hodierna. Maffesoli (1998, p.116-117) conjectura a "exposição" como um espolio fenomenológico que subvenciona a construção de uma "alegação sensitiva", quer seja 
por conciliar num idêntico desenvolvimento organizado entre sujeito e mundo, quer por substituído certo idealismo tradicional, desde Husserl, por uma "ascensão da convicção de horizonte", onde o entendimento causal é superado pela inquirição expositiva do ser no mundo.

Numa interpretação próxima, Onfray (2006, p.68) demanda por uma "concepção corporal", a metodologia apresentada por ele alternativamente, ao conhecer que "desce dos céus", pois encontra-se nas emoções, na saúde e na doença, na força e na fraqueza do corpo. Na convicção de Lipovetsky (2004), a era moderna reivindica o entendimento das essenciais movimentações do indivíduo na cultura, manifestamente transitórias, independentes não apenas das nem das tradições, da moral, mas contudo, de eventos modulados, como por exemplo a moda, instituindo-se um raciocínio coerente, acessível somente no próprio suceder coletivo.

Por intermédio de inúmeros trajetos, a metodologia fenomenológica faz-se vigente nas reflexões contemporâneas e, preceituam tanto a corporificação, quanto a percepção, ao assentimento de uma relevante função em muitas delas, a obra de Merleau-Ponty reitera a sua contemporaneidade.

\section{UM CONTEXTO HISTORICO SOBRE AS CONCEPÇÕES DE FREUD ATINENTES AO CORPO}

Paulatinamente, em virtude do encorpamento da medicina em suas teses científicas concernentes ao corpo, a partir do século XIX uma crítica veemente aos médicos, mormente na Alemanha, aparece de modo progressivo. A supervalorização da extensão orgânica das patologias, despreza a patologia do indivíduo, suas particularidades inerentes ao subjetivismo, impõe-se gradualmente, dando origem a premência de se articular demais abordagens que, possibilitem a justaposição dos aspectos subjetivos observados nas patologias.

Primordialmente, uma retorica filosófica faz-se solicitada para o estabelecimento de uma cognição dos aspectos ligados a subjetividade e sua conexão com as doenças. Num ensaio de abrandamento a tais críticas, Victor Von Weizsaecker (1956/2011), médico neurologista, defende uma ideologia filosófica do vivo, fundando-se na ontogênese. Inspirado por Heidegger, Victor Von Weizsacker assevera a ideia de que a existência de cada indivíduo 
faz-se o fundamento para as doenças que acometem o organismo humano, iniciando-se desse modo uma análise que abarca a junção entre os as particularidades subjetivas do sujeito, suas patologias e obviamente seu corpo.

Celeremente, essas ideias far-se-ão recebidas pela sociedade médica, que organizam um novo ramo da medicina. Essas primordiais manifestações conduziram ao advento do posteriormente se definirá como medicina psicossomática.

Movidos por esses ideais, alguns médicos, suscetíveis à psicanálise, esfera da medicina que a essa época afirmava-se fulcral para o entendimento do indivíduo, vão interessar-se pelos desígnios freudianos.

Com os intentos psicanalíticos utilizados na metodologia médica clássica, assiste-se um desarraigamento de ideais psicanalíticos elaborados por intermédio da metodologia típica do tratamento analítico. O uso de determinadas definições, aproxima-se da sistematização da medicina psicossomática, contudo, por outro lado, distancia-se do metodologia clínica na qual faz-se fundada a teoria psicanalítica.

Esses movimentos teoréticos intensificam-se. Schilder (1935/1994) alvitra a concepção de "imagem do corpo", fundado nas concepções freudianas acerca do Eu corpóreo. Advindo-se de ideias concebidas pela neurologia, Schilder examina que um reflexo do corpo próprio faz-se oriunda progressivamente com base nas emoções e concepções advindas do corpo. Contudo, essa "imagem do corpo" faz-se verdadeiramente uma construção contingente, como relembra apropriadamente Fédida (1971), e conduz à confusão do reconhecimento do corpo como a materialização do Eu.

Assim, prossegue Fédida, "a psicanálise não é uma psicologia do Eu", e toda trajetória proposta pela psicanálise freudiana "é uma pesquisa que, evitando se deixar pegar pela ilusão de um realismo do corpo-função ou de um corpo-imagem ou do corpo-vivido, fica atenta ao que do corpo reside nas palavras, se inscreve nos rastros, fica gravado na memória ao ponto de somente aparecer como reminiscência" (FÉDIDA, 1971, p.117). 
Restituindo-se, a ótica da teoria da psique do corpo que, para além de irromper com a perspectiva biológica, só deve concebê-la baseada nas utopias geradas pelos ensejos de ímpeto singular e com significados expressos através da linguagem.

Freud (Freud \& Breuer, 1895/1996) idealizava sua ótica do mecanismo psíquico com fulcro nas manifestações corporais. Desde a origem da psicanálise o corpo reitera sua composição. Na sua acepção de corpo, Freud afasta-se da ascendência da biologia e insere suas apresentações corpóreas no prisma intrapsíquico (ASSOUN, 1997). Não faz-se a doença o ponto crucial, mas o modo como o corpo atua nos processos inconscientes manifestos na elaboração do sintoma.

Com base nas questões teórico-clínicas acerca das ocorrências corpóreas que Freud, em seu texto "Estudos sobre a histeria" (Freud \& Breuer,1996, p.1895), desenvolve progressivamente a definição de inconsciente e propõe-se a remodelação da psique através do corpo.

\section{O DIREITO AO CORPO}

O indivíduo apresenta insignes esboços típicos, fazendo-se múltiplos os modos de projetar-se sua personalidade na vivencia social. Com o objetivo de proporcionar um condizente entendimento aos tópicos do assunto, assim como conferir um máximo delineamento jurídico as projeções, trivialmente subordinam-se os direitos da personalidade a inúmeras categorias classificatórias, especialmente as que expõem de modo segmentado os aspectos inerentes à integridade física, bem como às questões espirituais ou ainda morais do $\operatorname{ser}^{3}$.

No entanto, apartadamente as classificações encontradas e dos juízos a elas manifestos, faz-se imperativo acolher que o direito pertinente ao próprio corpo faz-se regularmente apensado entre os direitos à integridade física e abarca os direitos que concedem ao ser humano o exercício da capacidade acerca de seu próprio corpo, expandi-lo e protegê-lo contra ofensas de terceiros ${ }^{2}$, abrangendo-se as ações praticadas em vida, com aplicabilidade ainda em vida, bem como, ações experimentados com fruição de efeitos post mortem, como por exemplo, o ato de destinar o inato cadáver. 
Imprescindivelmente, deve-se escrutinar que não obstante o direito ao próprio corpo chegue, categorizado como um direito relacionado à compleição física, torna-se compreensível não se adotar um olhar reducionista, como se tudo se deliberasse nesse caráter orgânico, visto a pessoa ser mais que sua subsistência biológica. Fundamentado no corpo, eixo do ser, que emana direitos peculiares ao mesmo, como materialidade e os direitos atribuídos a ele como etiologia do espírito, motivo pelo qual assume-se relevância fulcral nas reflexões acerca dos direitos da personalidade ${ }^{3 .}$

O direito ao corpo advêm-se, contudo, comportando o alento de inúmeras correntes filosóficas e, experimentando a colisão dos atuais ramos do conhecimento angariados pelas

${ }^{3}$ Orlando Gomes subdivide os direitos da personalidade em duas classes, abrangendo, os direitos à integridade física (o direito à vida, o direito ao próprio corpo e o direito ao cadáver) e os direitos à compleição moral (que abrangem o direito à honra, à liberdade, ao recato, à imagem, ao nome e o direito moral do autor (GOMES, Orlando. Direitos de Personalidade. Revista de Informação Legislativa, setembro de 1966, p. 43). De outro lado, Santos Cifuentes categoriza os direitos da personalidade em três vértices, abarcando os direitos à integridade física (direito à vida, direito ao corpo, direito de morrer), os direitos à integridade espiritual (direito à honra, direito à imagem, direito à intimidade, direito à identidade) e o direito à liberdade (CIFUENTES, Santos. Derechos personalíssimos. $2^{\mathrm{a}}$ ed. Buenos Aires: Astrea, 1995, p. 229). Atentem-se, contudo, as análises de tais compartimentalizações, sob a alegação de que não detém teor cientifico algum e muito menos impulsionam a plena salvaguarda a personalidade, pois cogitam categorizar os direitos da personalidade, em prejuízo a aclamação de um direito genérico de personalidade. Nesse contexto: SZANIAWSKI, Elimar. Direitos da personalidade e sua tutela. São Paulo: Revista dos Tribunais, 2005, p. 228.

ciências biológicas, motivo pelo qual passou-se - e até o momento passa - por incessantes mutações, que impõem-se a contínua analise da sua temática.

\subsection{A consecução hodierna do direito ao corpo}

O ser biologicamente humano - ou de forma mais precisa, o corpo humano - faz-se o elemento arraigado ao afluência terrestre, o fundamento orgânico para o existir, bem como para o movimento entorno da condição de pessoa. Faz-se, sobretudo, a maneira de colocar-se no mundo e com ele atempar uma ligação. Existindo, um horizonte material, um subsidio objetivo, motivo pelo qual o direito da personalidade a ele concernente jamais poderá reduzirse a mero abstraimento jurídico, sujeito as normas naturais.

Cumpre-se assentar, no entanto, que o corpo também não reduz-se a um aspecto puramente biológico, contudo, a um complexo representativo, um ensejo para a manifestação 
do indivíduo. O corpo transpõe a materialização da identidade do ser, num grau rigorosamente peculiar e distintivo, que por vezes exerce uma relevante função na identificação do ser como participante da coletividade.

Imperativo, aglutinar as bases fornecidas pelas múltiplas convicções oriundas das ciências naturais com subsídios guiados, demasiadamente pelas ciências humanas ou, ainda, pela filosofia.

Efetivamente, as ciências humanas reivindicam a analise "do homem, numa reflexão dos seus inúmeros objetos. De maneira elucidativa, a filosofia, apartada das demandas científicas, traz à tona o aspecto do amago e da paridade humana, podendo-se, por conseguinte, falar-se em humanidade (WOLFF, Francis. 2012, p. 76).

Na filosofia moderna, faz-se a diferenciação, no ser humano, entre o corpo como eixo material (integralidade física) e como compleição (integralidade biológica). O corpo faz-se, prisma constitutivo e expressivo do ser humano, ou seja, dota-se de uma de uma qualidade intencional que sobrepuja o grau do físico e do biológico (VAZ, Henrique C. de Lima. 2011, p. 177-178).

Nessa ótica, intermediado pelo próprio corpo que o ser humano organiza-se em meio a coletividade, incumbindo-se do objetivismo do corpo físico-biológico ressignificando-o em inúmeros planos, todos devidamente estruturados entre si. Essa intermediação entre o corpo dado e o corpo próprio que permite que ele se faça um corpo estreitamente humano, constituindo-se assim, uma intencionalidade subjetiva (físico-biológica e psíquica) e uma intencionalidade intersubjetiva (social e cultural) (VAZ, Henrique, 2011, p.180-181) através da qual o indivíduo situa-se no paradoxo tempo-espaço e impulsiona sua sistematização social, cultural e psicológica em meio a coletividade (CIFUENTES, Santos, 1995, p. 231232).

O corpo faz-se o fulcro de convergência em meio aos fenômenos de índole orgânica e social do indivíduo, motivo pelo qual não deve fazer-se examinado apenas pelo seu aspecto instrumental, contudo, deve-se observar seu caráter expressivo (DAOLIO, Jocimar, 2006, p. 55). Efetivamente, o mistério primordial com que o ser depara-se em sua existência é o seu próprio corpo, que arrazoa colocar-se no mundo e sobre o qual acumulam-se os indícios de absorção cultural e sociabilização, no intuito de alcançar coadunabilidade ou, ainda, 
manifestar seu axioma, devido ao qual faz-se ensejo basilar para a estruturação da identidade pessoal.

Evidentemente que, sob o prisma dos direitos da personalidade, o corpo não consubstancia-se num objeto, exatamente por isso, busca-se evitar sua coisificação (CIFUENTES, Santos. 1995, p. 290), advinda da tendência patrimonialista. Ratifica-se, por conseguinte, que o corpo institui-se apenas, um dos subsídios constitutivos do ser, tão somente daquela pessoa, pois o "indivíduo faz-se aquilo que é exclusivamente seu" (Lord Cottenham, 1890, p. 205).

Inobstante, não tratar-se de uma relação fundada unicamente na simples aplicabilidade - apesar de contemporaneamente fazer-se vigente esse olhar modulado, entre o ser e seu próprio corpo. O corpo faz-se um componente indissolúvel, da unicidade do ser e de seu próprio existir (PERLINGIERI, Pietro. 1972, p 183).

A elocução, "direito ao corpo" deve ser concebida como uma maneira de ressaltar que o corpo deve voltar-se à realização pessoal do ser, à estruturação do seu desígnio particular e à sua própria dignidade. Não servindo-se, ademais, como instrumento para atender a interesses alheios, quer sejam privados, estatais, religiosos ou sociais.

\section{ACHEGAMENTOS E INTERLOCUÇÕES: MAUSS E MERLEAU-PONTY}

Constata-se que tanto Merleau-Ponty quanto Mauss, por intermédio de trajetórias distintas, esbarraram-se na qualidade factual do indivíduo, como o desenlace para o óbice que a ciência colocou-se em face ao dualismo cartesiano. Dado que, o indivíduo, a partir de sua obstinada manifestação no mundo, faz-se mais do que um ser munido de singularidade psíquica e ainda muito mais do que uma espécie meramente biológica.

Enquanto Mauss observa o "fato social total" como circunspecto simultaneamente pela tríplice dimensão psicológica, fisiológica e sociológica sintetizada na vivencia individual do ser, Merleau-Ponty arrazoa um "elemento encarnado", de um "ser no mundo", de um mundo não apenas pensado, mas também, vivido.

Entende-se mais claramente nesse momento, a razão pela qual os dois autores destinam um quinhão da sua obra a temática pertinente ao corpo. Nos dizeres de MerleauPonty o corpo faz-se rigorosamente a encarnação do ser no mundo, que mediador da inter- 
relação do indivíduo com ele. O autor ainda assevera que "[...] o corpo é o veículo do ser no mundo" (Merleau-Ponty, 1971, p.94).

Mauss já conduz-se a uma abordagem com relação ao corpo como provido, para além de um organismo biológico, de questões psicológicas e sociológicas. Uma mínima gesticulação humana incorre em manifestações fisiológicas, porém, também compõem-se pela singularidade psicológica, que caracteriza o autor do gesto de um outro individuo, e relacionase a uma coletividade que concede certa acepção a esse movimento.

Portanto, perscruta-se verificar se Merleau-Ponty abdicou-se do plano sociológico ressaltado em relação ao corpo por Mauss. Inobstante, múltiplas vezes, ser repreendido por isso, Merleau-Ponty não olvida-se da ótica social intrínseca ao corpo. Ao afirmar a aquisição de um hábito como "[...] a apreensão motora de uma significação motora" (Merleau-Ponty, 1971, p.154), ele considera que o indivíduo, por intermédio do seu corpo, instrui-se de movimentos específicos que recebem significados numa determinada conjuntura social. Ainda afirma o autor que "o corpo compreendeu e o hábito foi adquirido quando se deixou penetrar por uma nova significação, quando assimilou um novo centro significativo" (Merleau-Ponty, 1971, p.158).

Merleau-Ponty coteja o corpo a uma obra de arte, pontualmente por constituir-se num "nó de acepções vivas", comparação que provavelmente seria partilhada por Mauss. O que realmente aparenta distinguir Merleau-Ponty de Mauss não é a definição de corpo, mas sim o modo de refletir acerca do indivíduo no mundo. Em Merleau-Ponty, existe uma certa mobilidade que oriunda do ser encarnado, atribuído de um corpo próprio, com destino à convivência social. Contudo em Mauss, tal deslocamento mostra-se ser o contrário, um quinhão da estrutura social peculiar de um corpo, move-se rumo a um compendio individual.

Em Merleau-Ponty, o ser encarnado faz-se suscetível de semântica. Em Mauss, a coletividade encarna-se na experiência individual. Obviamente que essa diferenciação da trajetória investigativa, puramente formal, faz-se aclarada com a aproximação orgânica, tanto por um autor, como pelo outro. Merleau-Ponty, por exemplo, demonstra considerar a função das essências fundamental. De modo adverso, numa configuração de uma razão abstrata, como a presente na filosofia clássica, a essência faz-se representada no real, bem como lê-se em Reale e Antiseri: 
A fenomenologia [para Merleau-Ponty] é o "estudo das essências: por exemplo, a essência da percepção e a essência da consciência", mas "a fenomenologia também é uma filosofia que repõe as essências na existência e pensa que não se pode compreender o mundo e o homem senão com base na sua 'facticidade (REALE e ANTISERI, 2003, p. 615).

Merleau-Ponty parece interessar-se na mobilidade advinda de uma experimentação fenomenológica. Já Mauss mostra-se mais atento ao o que foi coisificado em razão das experimentações. Assim, pensar nas distinções precípuas que designam os autores assemelhase significar que a compreensão da percepção de subjetividade advém de enfoques dispares em cada um deles.

Mauss compreende o ser através do caráter de coletividade - não afasta a individualidade, porém, a evidencia como algo fulcral para entender o indivíduo - MerleauPonty manifesta como pano de fundo de sua filosofia, a ligação consciência-mundo (Reale; Antiseri, 2003). Não abdica-se da ligação entre o homem e a sociedade, longe disso, reputa tal mobilidade de significantes como algo estruturado coletivamente e, ofertado pela vivencia social.

Uma interlocução entre os autores alargaria consideravelmente os olhares acerca dos significantes de corpo e corporeidade, não apenas entendendo-se as diferenças teóricas entre ambos, mas superando-as, vez que os autores também dialogam em virtude da homogeneidade. Tanto para Mauss como para Merleau-Ponty, o corpo, municiado de conceitos socialmente compartilhados, faz-se a manifestação de uma dada sociedade.

Exatamente nessa interlocução que faz-se plausível perceber a oportunidade de alargamento do pensamento entorno do corpo e sobre o ser humano. Ao proporcionar o alargamento do debate sobre o corpo em face a um anteparo exclusivamente biológico para um horizonte mais concatenado, capaz de considerar o indivíduo como um ser no mundo e para o mundo, nesse aspecto as distinções entre os autores expressam-se minimamente.

Fundado em hipóteses que oriundam-se no modelo de teoria ampliada por Mauss e Merleau-Ponty, ainda que tenham num dado momento dissuadido a trajetória, diversos autores utilizam-se desse modo de interlocução problematizando-se demandas e investigações contemporâneas. 
Em plena década de 70, segundo Almeida (2004), Mary Douglas alargou os arrazoados de Mauss para expor a respeito dos "símbolos naturais" e considerava que o "durkheimianismo" de Douglas desagua-se na concepção de uma antropologia do corpo fundamentada em reflexões acerca dos usos figurados dos símbolos na duplicação da ordem social, que resultava numa forma de exame que acabara por definir uma sistematização classificatória.

Sob o ângulo basilar de Douglas, manifesta-se a recognição de que o corpo não faz-se estabelecido de maneira imperiosa pelo social. Contudo, ao que parece, as convicções entorno do corpo não têm-se assentado, de modo categórico, a interlocução entre os campos de atuação do social e do biológico. Como se numa brincadeira de "cabo de guerra" fizesse-se, de um lado, o determinismo social e, do outro, o determinismo biológico. A verdade é que, para utilizar-se dessa metáfora, seria necessariamente premente discernir que, num dado momento, a corda pender-se-ia para um dos lados e, nesse embate de forças, continuar-se-iam a atuar com significações limitadas por um vazio teorético.

Outro esforço de superação de tal vazio, foi a do antropólogo Thomas Csordas, legitimado por sua "antropologia da corporeidade". No prefácio de seu livro "Corpo, significado e cura", Steill (2008), que é o precípuo disseminador da obra de Csordas no Brasil, assevera que a visão de Csordas faz-se, ir para além do conceito, o que ele aspira é a compreensão da análise do que preceitua ser humano, enquanto um corpo no mundo. $\mathrm{O}$ autor assegura que o colóquio acerca da corporeidade, sobrepõe-se a interpretação e a exegese, sem, contudo, abarcar tais superfícies.

Combinando-se de modo produtivo as teorias de Merleau-Ponty sobre corpo e acuidade, bem como os escritos de Bourdieu sobre o "habitus", Csordas intenciona colapsar as bifurcações corpo e mente, sujeito e objeto entre outras. Não obstante o autor apresentar como ponto de partida a manifestação religiosa, substancialmente a partir do entendimento acerca dos fenômenos de cura, para ampliar suas alegações, sua teorética pode ser desmembrada em múltiplas investigações de outro escopo, incluindo-se analises que vislumbrem o domínio de quesitos intrínsecos aos moldes da corporeidade. 
Uma das substanciais argumentações de Csordas faz-se inerente as extensões individuais vigentes na mobilidade, ou seja, na manifestação corpórea, escapando-se ao elóquio, porém, não reduzem-se a ele. Relevante perceber que, ao redigir seu "modelo da corporeidade", ele transporta para o texto princípios imperiosos do pensamento fenomenológico e aponta-se como conversar com as concepções sociológicas de Bourdieu. Ao mencionar Bourdieu, ele não desconsidera referenciar Mauss, bem como a forma como a concepção de "habitus" faz-se pertinente ao pensamento maussiano.

Associadamente ao ensejo de Merleau-Ponty de demover a investigação da acuidade das coisas para o procedimento de coisificação, o propósito de Bourdieu faz-se ultrapassar a noção e a reflexão sobre fato social como um opus operantum, para a inquirição do modus operandi da existência coletiva. Seu estratagema propõe-se a ruir com o dualismo corpomente e signo-significante na definição de "habitus".

Essa definição foi introduzida por Mauss em seu estudo profícuo a respeito dos métodos do corpo, para concernir-se à somatória de costumes institucionalizados e em concordância com os padrões sociais do corpo. Na ótica de Mauss, foi uma maneira de organizar-se o que de outra maneira far-se-ia um alvoroço de condutas culturais padronizadas, fazendo-se jus a somente um parágrafo de produção.

Todavia, Mauss antecipa como um molde da corporeidade pode mediar-se dualismos básicos [...] em sua declaração de que o corpo é simultaneamente o objeto original sobre o qual o trabalho da cultura se desenvolve e a ferramenta original com a qual aquele trabalho se realiza. É, de uma vez, um objeto da técnica, um meio técnico e a origem subjetiva da técnica (Csordas, 2008, p.109).

Partindo-se originariamente da acepção de "hábito" de Mauss, o que Bourdieu concebeu foi inaugurar-se a convicção de um corpo coletivamente conhecedor, com suas aptidões e adversidades, ou ainda, em única palavra, com seus sentidos, o que num momento posterior, deu-se aplicado com regularidade por diversos pesquisadores (como Csordas), que semelhantemente, empenhou-se no rompimento das dicotomias e das dualidades nos ensaios concernentes ao corpo. 
Poder-se-ia, ademais, elencar outros exemplos de como a interlocução entre tais convicções far-se-ia frutífero na averiguação do entendimento sobre de que trata-se o corpo e o ser humano. Constituindo-se fato que, para o alargamento de uma discussão referente a corporeidade, mostra-se obvio considerar-se um "salto" propiciado por autores como Mauss e Merleau-Ponty e, mostra-se premente uma investida de construir uma espécie de convicção que dialogue com teorias do mesmo gênero, as quais não façam-se necessário a negação de determinados prismas humanos em prejuízo de outros.

Enfim, se o corpo faz-se condição primeva da inter-relação homem-mundo e se manifestações corpóreas extrapolam o discurso, demonstrando-se extensões individuais do que conceitua-se ser humano, de outro lado, "nosso contato conosco sempre se faz por meio de uma cultura, pelo menos por meio de uma linguagem que recebemos de fora e que nos orienta para o conhecimento de nós mesmos" (Merleau-Ponty, 2004, p.49). Assim, considerar-se as extensões subjetivas individuais, sem contudo, abdicar-se das coletivas, e assim sucessivamente, faz-se compreender, como assevera Merleau-Ponty (2004, p.50)

\section{CONSIDERAÇÕES FINAIS:}

Os ensaios de Marcel Mauss e Maurice Merleau-Ponty, no que concerne às aos ângulos concebidos pelo sistema simbiótico entre o corpo e a corporeidade, propõem-se relevantemente a sobrepor a bifurcação inaugurada por Descartes entre a matéria pensante e a o corpo. Buscaram veementemente o alargamento da discussão e ao desenvolvimento de delineios de uma cognição que transpusesse o paradigma tradicional alcançado pelos arbítrios naturais, buscando-se torna-los aptos a colaboração para uma institucionalização da investigação acerca do homem como ser social.

O diálogo entre os autores possibilitou uma verossímil ampliação do pensamento acerca do corpo, do ser humano, bem como consubstanciou a consolidação do paradigma de corporeidade. A partir desse alargamento, da discussão a respeito do corpo defronte a um anteparo puramente biológico para um panorama mais conectado, apto a refletir o indivíduo como um ser no mundo e para o mundo.

Com o alargamento das convicções concernentes ao corpo, fez-se admissível estatuirse de maneira mais imperativa, o corpo humano como componente afincado ao amago 
orgânico para a existência, assim como para a mobilidade acerca da condição de ser. Faz-se, sobremaneira, o colocar-se no mundo e estabelecer com ele uma ligação. Existindo, para além de uma perspectiva material, um ensejo objetivo, razão pela qual oriunda-se o direito da personalidade, a ele concernente. Não podendo-se reduzi-lo a mera abstração jurídica, sujeita as normas naturais. O corpo transpõe-se a substancialização da convergência do ser, num nível sistematicamente especifico e emblemático, que incumbe uma considerável incumbência no processo de recognição do ser como parte da coletividade.

Imperioso a anexação dos fundamentos providos pelas diversas concepções advindas das ciências naturais, em demasia pelas ciências humanas e, ainda, pela filosofia. Verdadeiramente, as ciências humanas propõem-se ao estudo do ser, numa consideração aos seus diversos desígnios. Assim, numa perspectiva mais inequívoca, a filosofia, denota a distinção entre o corpo como eixo físico e como compleição biológica. O corpo mostra-se, a esfera constitutiva e expressiva do ser humano, dotando-se de uma vicissitude que sobrepuja a gradação entre o físico e o biológico.

A locução, "direito ao corpo" concebe-se sua significação de modo a salientar que o corpo deve-se voltar à concretização particular do ser, à consolidação de seu proposito pessoal e à sua inerente dignidade. Não prestando-se, como mecanismo para o atendimento de interesses de terceiros, independentemente de serem privados, estatais, religiosos ou sociais.

Finalmente, para aprofundar-se na seara da corporeidade, faz-se premente além da reflexão acerca da relação homem-mundo, reverberar-se o grande salto, promovido pelos autores Mauss e Merleau-Ponty, além das demais interlocuções propostas, para a consolidação de teorias que demonstrem a equivalência entre os prismas humanos.

\section{REFERENCIAS}

ASSOUN, P. L. Corps et symptôme. Paris: Anthropos.1997.

BOURDIEU, P. A economia das trocas simbólicas. São Paulo: Perspectiva, 2009.

BOURDIEU, P. Questões de Sociologia. Lisboa: Fim de Século, 2003.

CIFUENTES, Santos. Derechos personalíssimos. 2.ed. Buenos Aires: Astrea, 1995, p. 231232.

CSORDAS, T. Corpo, significado, cura. Porto Alegre: Editora da UFRGS, 2008. 
DAOLIO, Jocimar. Corpo e identidade. In: MOREIRA, Wagner Wey (org.). Século XXI: A era do corpo ativo. Campinas: Papirus, 2006, p. 55.

DONEDA, Danilo. Os direitos da personalidade no Código Civil. Revista da Faculdade de Direito de Campos. Ano VI, nº 6, jun. de 2005, p. 86

DOUGLAS, Mary. Símbolos Naturais.3.ed. Routledge. Londres. 2003.

FÉDIDA, P. L'anatomie dans la psychanalyse. R.F.P., 1971.p.109-126.

FÉDIDA, P. La question de la théorie somatique dans la psychanalyse. Psychanalyse à l'Université,, 1978. 626p.

FREUD, S. Le cas Dora. In: Les cinqs analyses. Paris: PUF. 1954.P. 1-191

FREUD, S. Three essays on the theory of sexuality. S. E., v. VII. London: The Hogarth Press.

FREUD, S. The Psycho-analytic view of psychogenic disturbance of vision. S. E., v. XI. London: The Hogarth Press.1975

FREUD, S. Pour introduire le narcissisme. Euvres completes de psychanalyse), v. XII. Paris: PUF. 2005.

FREUD, S. Lettre de Freud à Groddeck du. In: Groddeck, G. Le ça et le moi. Paris: Gallimard. 1977.

FREUD, S. Le moi et le ça. Euvres completes de psychanalyse, v). XVI. Paris: PUF.1923.

FREUD, S. Le problème économique du masochisme. Euvres completes de psychanalyse, v. XVII. Paris: PUF.1924

FREUD, S. \& BREUIER, J. Etudes dur l'hystérie. Paris: PUF.1996.

FURLAN, R.; BOCCHI, J. C. O corpo como expressão e linguagem em MerleauPonty. Estudos de Psicologia, Natal, n. 8, 2003. p. 445-450.

GOMES, Orlando. Direitos de Personalidade. Revista de Informação Legislativa, setembro de 1966, p. 43.

LÉVI-STRAUSS, C. Introdução à obra de Marcel Mauss. In: MAUSS, M. Sociologia e Antropologia. São Paulo: EDU/EDUSP, v. 2.1974.

LIPOVETSKY, G. Os tempos hipermodernos. 3. ed. São Paulo: Barcarolla, 2004.

LORD COTTENHAM, citado por WARREN, Samuel D.; BRANDEIS, Louis D. The right to privacy, Harvard Law Review, IV, nº 5, December, 1890, p. 205. 
MAFFESOLI, M. Elogio da razão. 2. ed. Petrópolis, RJ: Vozes, 1998.

MAUSS, M. Sociologia e Antropologia. São Paulo: EDU/EDUSP, 1974.

MERLEAU-PONTY, M. Conversas-1948. São Paulo: Martins Fontes, 2004.

MERLEAU-PONTY, M. De Mauss a Claude Lévi-Strauss. In: MERLEAU-PONTY, M. Os pensadores: textos selecionados. São Paulo, Abril Cultural, 1980.

MERLEAU-PONTY, M. Fenomenologia da percepção. Rio de Janeiro: Freitas Bastos, 1971.

MERLEAU-PONTY, M. O visível e o invisível. 3. ed. São Paulo: Perspectiva, 1992.

MERLEAU-PONTY, M. Signes. Paris: Gallimard, 1960.

ONFRAY, M. La puissance d'exister. Paris: Grasset, 2006.

PERLINGIERI, Pietro. La personalitá umana nell"eordinamento giuridico. Camerino: Jovene, 1972.

Perfis do direito civil: introdução ao direito civil constitucional. Tradução de Maria Cristina de Cicco. Rio de Janeiro: Renovar, 2007.

REALE, G.; ANTISERI, D. História da filosofia. 1ª ed. v.3.Paulus, São Paulo.2018.

SZANIAWSKI, Elimar. Direitos da personalidade e sua tutela. São Paulo: Revista dos Tribunais, 2005, p. 228

STEILL, C. A. Prefácio. In: CSORDAS, T. Corpo, significado, cura. Porto Alegre: Editora da UFRGS, 2008.

VAZ, Henrique C. de Lima. Antropologia filosófica. São Paulo: Loyola. 11 a ed., 2011, p. 177-178.

VON WEIZSAECKER, V. (1956/2011). Pathosophie. Grenoble: Millon.

WACQUANT, L. Corpo e alma: notas etnográficas de um aprendiz de boxe. Rio de Janeiro: Relume Dumará, 2002.

WOLFF, Francis. Nossa humanidade: de Aristóteles às neurociências. Tradução Roberto Leal Ferreira. São Paulo: Unesp, 2012, p. 76. 